\title{
Analytical Method for Simultaneous Determination of Pesticides and Pesticide Transformation Products in Water Environment Using GC-MS and LC-MS/MS
}

\author{
Takashi KONDO*, Miho SAITO*, Takashi KAMEYA*, Koichi FUJIE*, Taku \\ MATSUSHITA**, Hirokazu TAKANASHI*** \\ *Division of Natural Environment and Information, Faculty of Environment and Information \\ Sciences, Yokohama National University, 79-7, Tokiwadai, Hodogaya, Yokohama 240-8501, \\ Japan \\ **Department of Environmental Engineering, Faculty of Engineering, Hokkaido University, \\ N13W8, Sapporo 060-8628, Japan \\ ***Department of Chemistry, Biotechnology, and Chemical Engineering, Graduate School of \\ Science and Engineering, Kagoshima University, 1-21-40, Korimoto, Kagoshima, \\ Kagoshima 890-0065, Japan
}

\begin{abstract}
Exposure to chemicals and their transformation products is important for evaluating environmental risk. In this study, the analytical method for both pesticides and pesticide transformation products (PTP) in water environments was developed. Eleven pesticides were selected based on the amount of their use in Kanagawa, Japan. According to previous literature research for PTP which have been found in hydrolysis and/or photolysis, 77 PTP could be enumerated. Among them, 30 commercially available PTP and their 11 parent pesticides were tested in this study. The detection sensitivity for pesticides and PTP was evaluated using GC-MS and LC-MS/MS. Using GC-MS, 31 compounds could be detected with a limit of quantification (LOQ) of $10-50 \mathrm{ng} / \mathrm{mL}$. To achieve detection of GC-MS-unfavorable compounds and more sensitive detection by LC-MS/MS, two atmospheric pressure ionization methods (electron spray ionization (ESI) and atmospheric pressure chemical ionization (APCI)) were assessed. Comparison of the LOQs demonstrated that the ESI method achieved more sensitive analysis than the APCI method. Also, LC-ESI-MS/MS showed higher sensitivity $(<1 \mathrm{ng} / \mathrm{mL})$ for the 11 compounds. As a result, except for 3 PTP, all pesticides and PTP were detected by the method developed. This analytical method can be applied to determine pesticides and PTP in environmental water samples.
\end{abstract}

Keywords: GC-MS, LC-MS/MS, pesticide, pesticide transformation product in water environments, simultaneous analysis

\section{INTRODUCTION}

Pesticides, which are widely used in agriculture for a consistent food supply, belong to many different chemical groups. These chemicals can be transformed in natural environments by hydrolysis and photolysis among other means. Spraying of a variety of pesticides further creates various pesticide transformation products (PTP) in water environments and pollution by these substances is thus now an increasing concern with regard to not only environmental risk but also health risk. Because of this concern, pesticides and their PTP in water matrices including groundwater and surface water have been determined elsewhere (Albanis et al., 1998; U. S. Geological Survey, 2003; Hladik et al., 2008; Iwafune et al., 2010). These studies demonstrated that PTP could be found in higher concentrations than their parent pesticides in water environments; however, these studies mainly focused on the major PTP of target pesticides. On the other hand, the molecular structure of some PTP, which are not mutagens and are thus

Address correspondence to Takashi Kameya, Faculty of Environment and Information Sciences, Yokohama National University, Email: kameya@ynu.ac.jp Received May 10, 2012, Accepted July 24, 2012. 
neglected by regulations, could change to become mutagenic by chlorination in water purification plants (Kishida et al., 2010). Kishida et al. (2010) reported that 3-methyl-4nitrophenol (3M4NP), a PTP of the organophosphorus insecticide fenitrothion, has 19 times greater mutagen formation potential (MFP) than the MFP of the parent, fenitrothion. Our recent monitoring results have shown that 3M4NP was found in higher concentrations than fenitrothion in rivers in Kanagawa, Japan (Kameya et al., 2012); thus, besides the identification of such substances, the fate of pesticides and all their possible PTP in water environments should be assessed. However, such a method development and a monitoring report for multiclass pesticides and PTP in water environment have not reported. Therefore, the method development to identify and quantify these substances simultaneously is indispensable.

To detect pesticides and PTP, gas chromatography (GC) and liquid chromatography (LC) equipped with mass spectrometer(s) (MS) have been widely accepted. The GC-MS system provides a robust analytical method for the detection of volatile and thermally stable compounds with high selectivity and sensitivity. For non-volatile or thermally unstable compounds, LC-tandem mass spectrometry (LC-MS/MS) is a powerful method. For most polar pesticides, LC-MS/MS has achieved much better selective and sensitive detection than GC-MS (Alder et al., 2006). As for LC-MS/MS analysis, there are two types of ionization: electron spray ionization (ESI) and atmospheric pressure chemical ionization (APCI).

Hence, the objective of this study is the development of an analytical method for both pesticides and PTP simultaneously using GC-MS and LC-MS/MS. First, to develop such a method, selected pesticides and PTP were subjected to the development of the method by using GC-MS. Retention time, monitoring ion and characterization ions of each substance were identified. After that, limit of quantification (LOQ) in GC-MS analysis was determined. For further sensitive detection, LC-MS/MS analysis was performed for both the ESI and APCI methods. After identification of transition ions and retention time, LOQs in each ionization methods were determined. The developed method in this study should contribute to the monitoring of multiclass pesticides and PTP in water matrices simultaneously, and to the understanding of their environmental fate.

\section{MATERIALS AND METHODS \\ Reagents and Chemicals}

The pesticides and their PTP were purchased from Wako Pure Chemical Industries (Osaka, Japan), Tokyo Chemical Industry (Tokyo, Japan), Sigma-Aldrich (Tokyo, Japan), Nacalai Tesque (Kyoto, Japan) and CosmoBio (Tokyo, Japan). Purity of these chemicals ranged from $95 \%$ to $99 \%$ except for diethyl phosphate $(75 \%)$. Acenaphthene-d10, naphthalene-d8, fluoranthene-d10 and phenanthrene-d10 were supplied as a mixture from RESTEK (Bellefonte, PA, USA) and utilized as internal standards (ITSDs) for GC-MS analysis. Each stock standard solution (100 to 2,000 $\mu \mathrm{g} / \mathrm{mL}$, depending on the solubility of each) and ITSD were prepared by dissolving in acetone or methanol and storing at $-25^{\circ} \mathrm{C}$. Standard solutions were diluted with adequate solvent (acetone for GC-MS and methanol for LC-MS/MS) prior to fragmentation analysis. The working standard solutions of the mixtures were prepared 
by the appropriate dilution of the stock solutions at concentrations ranging from 10 $\mathrm{ng} / \mathrm{mL}$ to $10 \mu \mathrm{g} / \mathrm{mL}$ for GC-MS and from $100 \mathrm{pg} / \mathrm{mL}$ to $100 \mathrm{ng} / \mathrm{mL}$ for LC-MS/MS. Acetone for residual pesticide analysis, methanol and ultra-pure water of HPLC-grade, and ammonium formate were obtained from Wako Pure Chemical Industries (Osaka, Japan).

\section{GC-MS analysis}

For the observation of fragment patterns, each standard solution was loaded to a GC-MS system (QP2010 plus, Shimadzu, Kyoto, Japan) which was operated under the following conditions: column, Agilent Technologies J\&W DB-5ms $(30 \mathrm{~m} \times 0.25 \mathrm{~mm}$, $0.25 \mu \mathrm{m}$; Tokyo, Japan); carrier gas, helium with a flow rate of $2.13 \mathrm{~mL} / \mathrm{min}$ at constant flow; injector temperature, $220^{\circ} \mathrm{C}$; transfer line, $250^{\circ} \mathrm{C}$; ion source, electron impact (EI) at $70 \mathrm{eV}$; source temperature, $230^{\circ} \mathrm{C}$; injection volume, $1 \mu \mathrm{L}$; injection mode, splitless; programmed oven temperature, $50^{\circ} \mathrm{C}$ for $2 \mathrm{~min}$ and ramped to $170^{\circ} \mathrm{C}$ at $10^{\circ} \mathrm{C} / \mathrm{min}$, then to $200^{\circ} \mathrm{C}$ at $3^{\circ} \mathrm{C} / \mathrm{min}$, finally to $300^{\circ} \mathrm{C}$ at $10^{\circ} \mathrm{C} / \mathrm{min}$, and kept for $10 \mathrm{~min}$. These conditions were determined for the detection of much target analytes as referred to the methods by Kadokami et al. (2004). Also, ITSDs were also utilized according to Kadokami et al. (2004) and adequate ITSD for each substance was automatically fixed by GC-MS software (GCMS solution ver. 2.71, Shimadzu) according to retention time. After the determination of fragment ions for monitoring ion and characteristic ions, the complete mixed standards were analyzed using the selected ion monitoring (SIM) mode. The LOQ was set to the lowest concentration, which gave a signal-to-noise $(\mathrm{S} / \mathrm{N})$ ratio of $\geq 10$ for the most intense peak.

\section{LC-MS/MS analysis}

The sensitivity of LC-MS/MS was assessed using a triple quadrupole mass spectrometer (TSQ Quantum Access MAX, Thermo Fisher Scientific, Yokohama, Japan) equipped with Accela HPLC (Thermo Fisher Scientific). For each ionization method, ESI and APCI, two multiple reaction monitoring (MRM) transitions and adequate collision energy for all substances were determined by direct injection of standard solutions $(\geq 50$ $\mathrm{ng} / \mathrm{mL})$ with methanol/2 $\mathrm{mM}$-ammonium formate buffer $(50: 50)$.

After that, LC was operated using a Heypersil GOLD column $(50 \mathrm{~mm} \times 2.1 \mathrm{~mm}, 1.9$ $\mu \mathrm{m}$; Thermo Fisher Scientific, Yokohama, Japan) and the column temperature was kept at $40^{\circ} \mathrm{C}$. The mobile phase consisted of $2 \mathrm{mM}$ ammonium formate (A) and methanol (B). The applied gradient elution was set as follows: start with $1 \% \mathrm{~B}$, increase to $30 \% \mathrm{~B}$ within $3 \mathrm{~min}$, maintain the isocratic condition for $3 \mathrm{~min}$, further increase to $99 \% \mathrm{~B}$ within $6 \mathrm{~min}$, return to the initial condition within $1 \mathrm{~min}$, and hold for the last $5.5 \mathrm{~min}$. The flow rate was kept constant at $200 \mu \mathrm{L} / \mathrm{min}$ and the injection volume was $5 \mu \mathrm{L}$. The operational conditions for the ESI method were set as follows: spray voltage, 3,000 V; tube lens voltage, $78 \mathrm{~V}$; ion transfer capillary temperature, $270^{\circ} \mathrm{C}$; vaporizer temperature, $450^{\circ} \mathrm{C}$; sheath gas $\left(\mathrm{N}_{2}\right)$ pressure, $50 \mathrm{psi}$; auxiliary gas $\left(\mathrm{N}_{2}\right)$ pressure, 15 units. The operational conditions for the APCI method were as follows: corona discharge current, $4 \mu \mathrm{A}$; tube lens voltage, $78 \mathrm{~V}$; ion transfer capillary temperature, $300^{\circ} \mathrm{C}$; vaporizer temperature, $300^{\circ} \mathrm{C}$; sheath gas pressure, $30 \mathrm{psi}$; auxiliary gas pressure, 0 units. The collision gas (argon) pressure was set at 1.5 mTorr for both operational methods. 


\section{RESULTS AND DISCUSSION}

\section{Selected pesticides and PTP}

According to the amount of pesticides in Kanagawa, Japan (Japan Plant Protection Association, 2007), and literature search for PTP using the ISI Web of Science database, 11 target pesticides were selected (Table 1). All the selected pesticides are regulated by Waterworks Law of Japan (Ministry of Health, Labour and Welfare) and the target values are also shown in Table 1. Although there are 77 PTP for the target pesticides, only 30 PTP listed in Table 1 were commercially available. Summary for the number of available and unavailable PTP of each pesticide is shown in Table 2. Commercially available PTP are roughly divided into two types: higher molecular weight PTP, which are primary metabolites such as oxon metabolites, and the lower molecular weight PTP, which have simple structures and could be sold for other research purposes. For example, there are 5 PTP for the organophosphorus insecticide acephate (Fig. 1). Only 1 higher molecular weight PTP (methamidophos) and 1 lower molecular weight PTP (dimethyl disulfide) were available. Other unavailable PTP were not tested in this study and further development of the method for the detection of these PTP is necessary.

Table 1 - Pesticides and PTP tested in this study and parameters of GC-MS analysis.

\begin{tabular}{|c|c|c|c|c|c|c|c|}
\hline $\begin{array}{c}\text { Pesticide } \\
\text { PTP }\end{array}$ & CAS RN. & $\begin{array}{c}\text { Target value }^{\mathrm{a}} \\
{[\mathrm{mg} / \mathrm{L}]}\end{array}$ & $\begin{array}{c}\text { Retention time } \\
{[\text { min] }}\end{array}$ & $\begin{array}{c}\text { Monitoring ion } \\
{[\mathrm{m} / \mathrm{z}]}\end{array}$ & $\begin{array}{c}\text { Characterization } \\
\text { ions }[\mathrm{m} / \mathrm{z}]\end{array}$ & ITSD $^{b}$ & $\begin{array}{c}\text { LOQ } \\
{[\mathrm{ng} / \mathrm{mL}]}\end{array}$ \\
\hline Acephate & $30560-19-1$ & 0.08 & 12.8 & 136 & 42,94 & $\mathrm{~A}$ & $<10$ \\
\hline Methamidophos & $10265-92-6$ & & 10.0 & 94 & $95,47,141$ & $\mathrm{~N}$ & $<10$ \\
\hline Dimethyl disulfide & $624-92-0$ & & N.D. & N.D. & N.D. & N.D. & N.D. \\
\hline Chlorothalonil & $1897-45-6$ & 0.05 & 18.1 & 266 & 264,268 & $\mathrm{P}$ & $<10$ \\
\hline Isophtalonitrile & $626-17-5$ & & 10.6 & 128 & 101,129 & $\mathrm{~N}$ & $<10$ \\
\hline Diazinon & $333-41-5$ & 0.005 & 18.0 & 179 & 137,152 & $\mathrm{P}$ & $<10$ \\
\hline Diazoxon & $962-58-3$ & & 17.6 & 137 & 273,134 & $P$ & $<10$ \\
\hline Diethyl phosphate & $598-02-7$ & & N.D. & N.D. & N.D. & N.D. & N.D. \\
\hline 2-Isopropyl-6-methyl-pyrimidine-4-ol & $2814-20-2$ & & 13.0 & 137 & 84,151 & A & $<10$ \\
\hline Dichlorvos & $62-73-7$ & 0.008 & 10.2 & 109 & 185,145 & $\mathrm{~N}$ & $<10$ \\
\hline Dimethyl phosphate & $813-78-5$ & & N.D. & N.D. & N.D. & N.D. & N.D. \\
\hline Disulfoton & $298-04-4$ & 0.004 & 18.3 & 88 & 89,60 & $\mathrm{P}$ & $<10$ \\
\hline Disulfoton-oxon & $126-75-0$ & & 16.9 & 88 & 60,89 & $\mathrm{P}$ & $<10$ \\
\hline Disulfoton-sulfoxide & $2497-07-6$ & & 11.4 & 97 & 125,153 & $\mathrm{~N}$ & $<10$ \\
\hline Fenitrothion & $122-14-5$ & 0.003 & 21.0 & 125 & 277,109 & $\mathrm{~F}$ & $<10$ \\
\hline Fenitrooxon & $2255-17-6$ & & 19.5 & 109 & 244,231 & $P$ & $<10$ \\
\hline Methyl parathion & $298-00-0$ & & 20.0 & 109 & 263,125 & $P$ & $<10$ \\
\hline Methyl paraoxon & $950-35-6$ & & 18.3 & 109 & 96,217 & $P$ & $<10$ \\
\hline 3-Methyl-4-nitroanisole & $5367-32-8$ & & 13.4 & 150 & 109,165 & A & $<10$ \\
\hline 3-Methyl-4-nitrophenol & $2581-34-2$ & & 14.7 & 136 & 77,153 & $\mathrm{~A}$ & $<10$ \\
\hline Trimethylphosphate & $512-56-1$ & & N.D. & N.D. & N.D. & N.D. & N.D. \\
\hline$m$-Cresol & $108-39-4$ & & N.D. & N.D. & N.D. & N.D. & N.D. \\
\hline Malathion & $121-75-5$ & 0.05 & 21.6 & 127 & 173,125 & $\mathrm{~F}$ & $<10$ \\
\hline Malaoxon & $1634-78-2$ & & 20.0 & 127 & 99,125 & $\mathrm{~F}$ & $<10$ \\
\hline D-(-)-Tartaric acid diethyl ester & $13811-71-7$ & & 11.7 & 104 & $76,29,133$ & A & $<10$ \\
\hline $\mathrm{L}-(+)-$ Tartaric acid diethyl ester ${ }^{\mathrm{c}}$ & $87-91-2$ & & 11.7 & 104 & 76,133 & A & $<10$ \\
\hline Diethyl L-(-)-malate & $691-84-9$ & & 10.5 & 117 & 89,71 & $\mathrm{~N}$ & $<10$ \\
\hline Diethyl maleate & $141-05-9$ & & 9.1 & 99 & 127,126 & $\mathrm{~N}$ & $<10$ \\
\hline Diethyl fumarate ${ }^{c}$ & $623-91-6$ & & 9.1 & 127 & $99,126,29$ & $\mathrm{~N}$ & $<10$ \\
\hline Methidathion & $950-37-8$ & 0.004 & 24.6 & 145 & $85,93,15$ & $\mathrm{~F}$ & $<10$ \\
\hline Methidathion-oxon & $39856-16-1$ & & 22.5 & 85 & 145,142 & $\mathrm{~F}$ & $<10$ \\
\hline Thiobencarb & $28249-77-6$ & 0.02 & 21.8 & 100 & 72,125 & $\bar{F}$ & $<10$ \\
\hline$p$-Chlorobenzyl alcohol & 873-76-7 & & 10.2 & 77 & 107,142 & $\mathrm{~N}$ & $<10$ \\
\hline$p$-Chlorobenzaldehyde & $104-88-1$ & & N.D. & N.D. & N.D. & N.D. & N.D. \\
\hline$p$-Chlorobenzoic acid & $74-11-3$ & & 11.4 & 139 & 156,111 & $\mathrm{~N}$ & 50 \\
\hline Thiophanate-methyl & $23564-05-8$ & 0.3 & N.D. & N.D. & N.D. & N.D. & N.D. \\
\hline Carbendazim & $10605-21-7$ & & N.D. & N.D. & N.D. & N.D. & N.D. \\
\hline 2-Aminobenzimidazole & 934-32-7 & & N.D. & N.D. & N.D. & N.D. & N.D. \\
\hline Pencycron & $66063-05-6$ & 0.1 & 16.3 & 125 & 127,180 & $\mathrm{P}$ & $<10$ \\
\hline Phenylurea & 64-10-8 & & 14.9 & 93 & 136,66 & A & $<10$ \\
\hline Aniline & $62-53-3$ & & N.D. & N.D. & N.D. & N.D. & N.D. \\
\hline
\end{tabular}


Table 2 - Summary for the number of commercially available PTP and unavailable PTP.

\begin{tabular}{lccc}
\hline \multicolumn{1}{c}{ Pesticide } & $\begin{array}{c}\text { Commercially } \\
\text { available PTP }\end{array}$ & $\begin{array}{c}\text { Unavailable } \\
\text { PTP }\end{array}$ & Total \\
\hline Acephate & 2 & 3 & 5 \\
Chlorotalonil & 1 & 7 & 8 \\
Diazinon & 3 & 3 & 6 \\
Dichlorvos & 1 & 0 & 1 \\
Disulfoton & 2 & 1 & 3 \\
Fenitrothion & 7 & 11 & 18 \\
Malathion & 6 & 5 & 11 \\
Methidathion & 1 & 8 & 9 \\
Pencycuron & 2 & 5 & 7 \\
Thiobencarb & 3 & 4 & 7 \\
Thiophanate-methyl & 2 & 0 & 2 \\
\hline
\end{tabular}

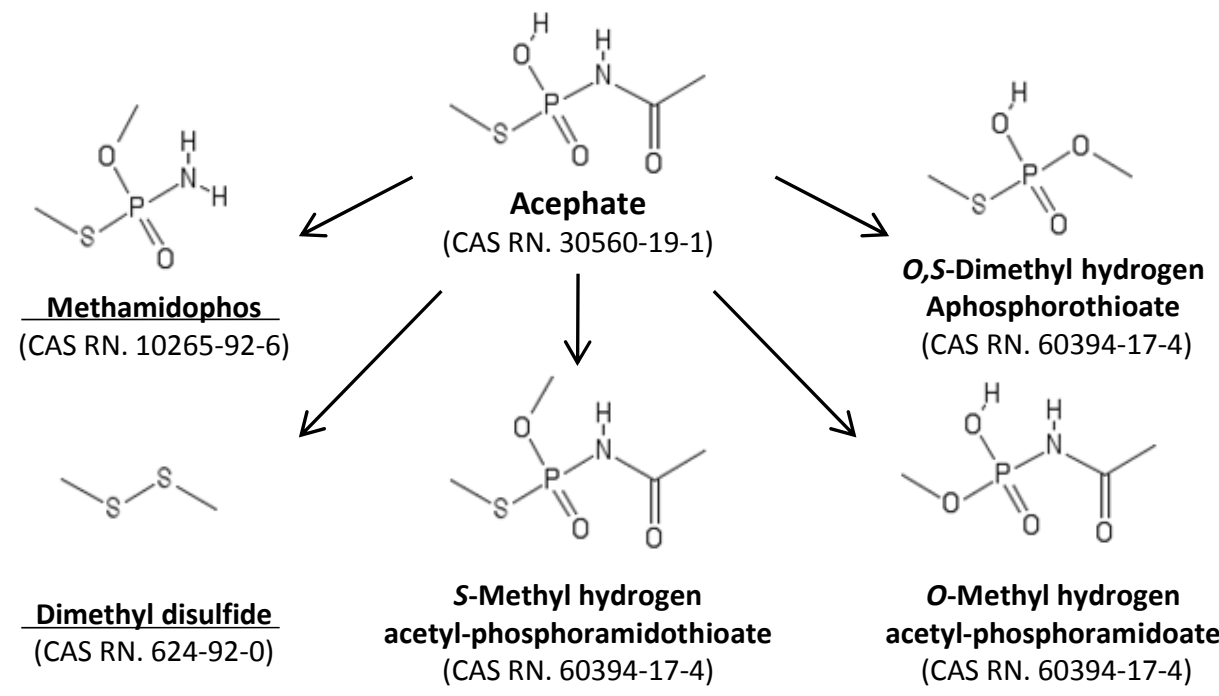

Fig. 1 - PTP of acephate. Commercially available PTP are underlined.

\section{GC-MS analysis for pesticides and PTP selected}

Residual pesticides analysis using GC-MS has been widely utilized. Among the tested 41 substances (11 pesticides and their 30 PTP), fragmentation patterns and their retention time were determined for 31 substances. The retention time for these substances ranged from 9.1 to 24.6 min, indicating that good separation was achieved. In Waterworks Law of Japan, GC-MS analysis has been utilized for the detection of all pesticides except for acephate and thiophanate-methyl. In this study, acephate and its PTP methamidophos could be detected the same as GC-MS-favorable pesticides, whereas thiophanate- methyl and its PTP were not detected. Two pairs of isomers (D,L-tartaric acid diethyl; diethyl maleate and diethyl fumarate), which are the PTP of malathion, were not distinguishable, so their LOQs were obtained by each representative (D-tartaric acid diethyl and diethyl maleate). Phosphoric esters, $p$-chlorobenzaldehyde, dimethyl disulfide and aniline were not detected by GC-MS in this study. For all the detectable substances, except for $p$-chlorobenzoic acid, LOQs were less than $10 \mathrm{ng} / \mathrm{mL}$ (Table 1). 


\section{Detection of selected pesticide and PTP using LC-MS/MS}

For the detection of pesticides and their PTP, LC-MS/MS analysis was applied. The MS spectra of substances tested in this study showed strong signals at $[\mathrm{M}+\mathrm{H}]^{+}$or $\left[\mathrm{M}+\mathrm{NH}_{4}\right]^{+}$. The MRM transitions of 28 substances using the ESI method are shown in Table 3 since those using APCI method for most substances did not differ significantly. For the detectable 27 substances, LOQs were equal to or less than $10 \mathrm{ng} / \mathrm{mL}$, whereas it was 20 $\mathrm{ng} / \mathrm{mL}$ for dimethyl phosphate (Table 3). Furthermore, among them, LOQs for 11 substances were less than $1 \mathrm{ng} / \mathrm{mL}$. The organochlorine fungicide chlorothalonil and its PTP were not observed. The MRM transitions of fenitrothion, methylparathion, 3-methyl-4-nitroanisole in positive mode, and 3-methyl-4-nitrophenol in negative mode, were confirmed by the infusion analysis in LC-ESI-MS/MS analysis; however, the LOQs were higher than the standard concentration tested in this study (data not shown). As for other carboxylic acids and alcohols, MRM transitions were confirmed in negative mode but these signals were very weak (data not shown).

Table 3 - Parameters in LC-MS/MS for pesticides and PTP analysis.

\begin{tabular}{|c|c|c|c|c|c|c|c|c|}
\hline \multirow{2}{*}{$\begin{array}{c}\text { Pesticide } \\
\text { PTP }\end{array}$} & \multirow{2}{*}{$\begin{array}{c}\text { Retention time } \\
\text { [min] }\end{array}$} & \multirow{2}{*}{$\begin{array}{c}\text { Precursor } \\
\text { ion }[\mathrm{m} / \mathrm{z}]\end{array}$} & \multicolumn{2}{|c|}{ 1st transition } & \multicolumn{2}{|c|}{ 2nd transition } & \multirow{2}{*}{$\begin{array}{c}\text { ESI } \\
\text { LOQ [ng/mL] }\end{array}$} & \multirow{2}{*}{$\begin{array}{c}\text { APCI } \\
\text { LOQ [ng/mL] }\end{array}$} \\
\hline & & & {$[\mathrm{m} / \mathbf{z}]$} & $\mathrm{CE}[\mathrm{V}]$ & {$[\mathrm{m} / \mathbf{z}]$} & CE [V] & & \\
\hline Acephate & N.D. & N.D. & N.D. & N.D. & N.D. & N.D. & N.D. & N.D. \\
\hline Methamidophos & N.D. & N.D. & N.D. & N.D. & N.D. & N.D. & N.D. & N.D. \\
\hline Dimethyl disulfide & N.D. & N.D. & N.D. & N.D. & N.D. & N.D. & N.D. & N.D. \\
\hline Chlorothalonil & N.D. & N.D. & N.D. & N.D. & N.D. & N.D. & N.D. & N.D. \\
\hline Isophtalonitrile & N.D. & N.D. & N.D. & N.D. & N.D. & N.D. & N.D. & N.D. \\
\hline Diazinon & 7.49 & 305 & 169 & 21 & 153 & 21 & 0.2 & 0.5 \\
\hline Diazoxon & 5.89 & 289 & 153 & 17 & 84 & 32 & 0.5 & 5 \\
\hline Diethyl phosphate & 0.72 & 155 & 99 & 14 & 81 & 32 & 0.5 & 0.5 \\
\hline 2-Isopropyl-6-methyl-pyrimidine-4-ol & 4.04 & 153 & 84 & 17 & 70 & 19 & 5 & 5 \\
\hline Dichlorvos & 5.13 & 221 & 109 & 17 & 127 & 14 & 2 & N.D. \\
\hline Dimethyl phosphate & 0.63 & 127 & 109 & 14 & 95 & 18 & 20 & 100 \\
\hline Disulfoton & 7.97 & 275 & 89 & 11 & 61 & 14 & 10 & 20 \\
\hline Disulfoton-oxon & 5.91 & 259 & 89 & 10 & 61 & 34 & 0.5 & 5 \\
\hline Disulfoton-sulfoxide & 5.43 & 291 & 185 & 11 & 157 & 19 & 0.5 & 2 \\
\hline Fenitrothion & N.D. & N.D. & N.D. & N.D. & N.D. & N.D. & N.D. & N.D. \\
\hline Fenitrooxon & 5.19 & 279 & 216 & 23 & 104 & 24 & 0.2 & 50 \\
\hline Methyl parathion & N.D. & N.D. & N.D. & N.D. & N.D. & N.D. & N.D. & N.D. \\
\hline Methyl paraoxon & 4.85 & 248 & 202 & 15 & 109 & 26 & 10 & N.D. \\
\hline 3-Methyl-4-nitroanisole & N.D. & N.D. & N.D. & N.D. & N.D. & N.D. & N.D. & N.D. \\
\hline 3-Methyl-4-nitrophenol & N.D. & N.D. & N.D. & N.D. & N.D. & N.D. & N.D. & N.D. \\
\hline Trimethylphosphate & 3.42 & 141 & 109 & 15 & 79 & 20 & 5 & 2 \\
\hline$m$-Cresol & N.D. & N.D. & N.D. & N.D. & N.D. & N.D. & N.D. & N.D. \\
\hline Malathion & 6.25 & 331 & 127 & 11 & 99 & 20 & 10 & 2 \\
\hline Malaoxon & 5.15 & 315 & 99 & 20 & 127 & 31 & 1 & 5 \\
\hline D-(-)-Tartaric acid diethyl ester & 4.18 & 224 & 133 & 12 & 161 & 10 & 10 & 100 \\
\hline L-(+)-Tartaric acid diethyl ester ${ }^{\mathrm{a}}$ & 4.18 & 224 & 133 & 12 & 161 & 8 & 10 & 100 \\
\hline Diethyl L-(-)-malate & 4.49 & 208 & 117 & 14 & 145 & 10 & 5 & 20 \\
\hline Diethyl maleate & 4.89 & 173 & 99 & 15 & 127 & 5 & 1 & 1 \\
\hline Diethyl fumarate $^{\mathrm{a}}$ & 4.89 & 173 & 99 & 13 & 127 & 8 & 1 & 1 \\
\hline Methidathion & 5.71 & 303 & 145 & 6 & 85 & 17 & 1 & 2 \\
\hline Methidathion-oxon & 4.72 & 287 & 145 & 8 & 85 & 18 & $<0.1$ & 2 \\
\hline Thiobencarb & 6.37 & 258 & 125 & 19 & 89 & 42 & 1 & 2 \\
\hline$p$-Chlorobenzyl alcohol & N.D. & N.D. & N.D. & N.D. & N.D. & N.D. & N.D. & N.D. \\
\hline$p$-Chlorobenzaldehyde & N.D. & N.D. & N.D. & N.D. & N.D. & N.D. & N.D. & N.D. \\
\hline$p$-Chlorobenzoic acid & N.D. & N.D. & N.D. & N.D. & N.D. & N.D. & N.D. & N.D. \\
\hline Thiophanate-methyl & 5.00 & 343 & 151 & 20 & 311 & 10 & 1 & 5 \\
\hline Carbendazim & 4.58 & 192 & 160 & 17 & 132 & 29 & 0.5 & 5 \\
\hline 2-Aminobenzimidazole & 4.23 & 134 & 92 & 92 & 65 & 32 & 0.5 & 5 \\
\hline Pencycron & 8.04 & 329 & 125 & 22 & 89 & 59 & 0.5 & 2 \\
\hline Phenylurea & 3.81 & 137 & 94 & 15 & 77 & 26 & 0.5 & 20 \\
\hline Aniline & 3.80 & 94 & 77 & 17 & 51 & 33 & 10 & 5 \\
\hline
\end{tabular}

a, The isomer was determined with another isomer. N.D., not determined. 
Compared to the APCI method, the ESI method achieved high sensitivity analysis for most substances (Table 3). Although higher sensitivity using the ESI method has also been reported (Wick et al., 2010; Maragou et al., 2011), both studies also reported that significant ionization suppression was confirmed using the ESI method due to the presence of non-volatile materials that inhibit the release of analytes into the gas phase (King et al., 2000). Thus, using environmental samples, an adequate ionization method could be optimized for each pesticide and its PTP.

Greater sensitivity and selectivity was obtained in LC-ESI-MS/MS rather than GC-MS in most pesticides and PTP. This result is consistent with the review by Alder et al. (2006) that LC-ESI-MS/MS achieved better performance than GC-MS in the analysis of all chemical classes of pesticides except for organochlorine pesticides such as chlorothalonil. However, different from the review, the organophosphate insecticide acephate and its PTP methamidophos exhibited very broad peaks between 0.7 to 4.0 min. One reason for this phenomenon may be solvent suitability. Mol et al. (2003) reported that peak broadening was confirmed in a larger injection volume when methanol was used as a solvent. Thus, solvent optimization would improve the sensitivity in future study. Using both GC-MS and LC-ESI-MS/MS, all pesticides and most of the PTP used in this study could be detected except for 3 PTP (dimethyl sulfide, $m$-cresol and $p$-chlorobenzaldehyde). The summary of LOQs is shown in Fig. 2. Most substances could be identified and quantified with LOQs of $0.1 \mathrm{ng} / \mathrm{mL}$ to $10 \mathrm{ng} / \mathrm{mL}$. Considering pre-concentration such as solid phase extraction (SPE), these LOQs are sufficient for the required pesticide analysis regulated by the Waterworks Law of Japan, and are enough to detect pesticides and PTP with trace concentrations in water environments.

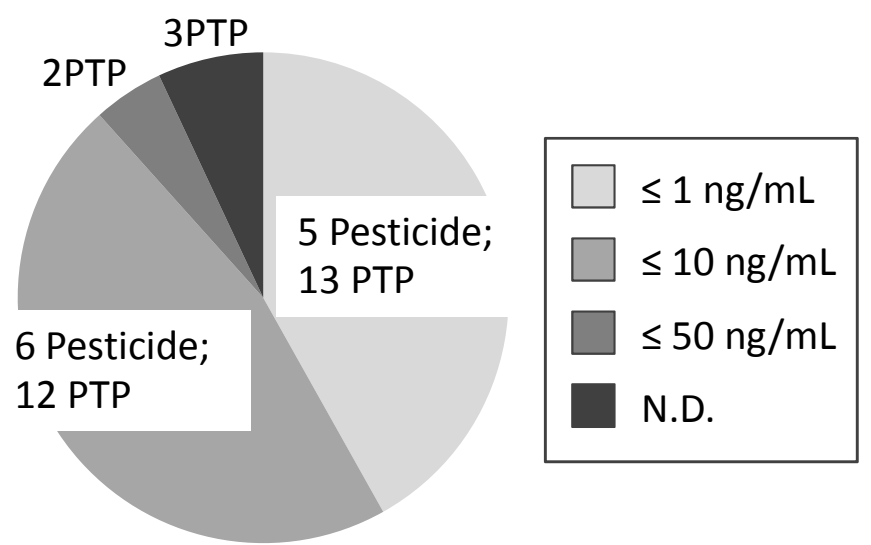

Fig. 2 - LOQs of pesticides and PTP tested in this study. The numbers in the figure indicate the numbers of substances. 


\section{CONCLUSIONS}

To develop an analytical method for both pesticides and PTP simultaneously, 11 pesticides and their 30 PTP were selected and subjected to analytical method development using GC-MS and LC-MS/MS. Parameters such as fragment patterns and retention times for each substance were determined (Table 1 and 3). All substances except for the 3 PTP (dimethyl sulfide, $m$-cresol and $p$-chlorobenzaldehyde) were detected by both GC-MS and LC-MS/MS. For environmental water samples, concentration using SPE is necessary due to their trace concentrations. Therefore, LOQs determined in this study are sufficient for the monitoring of pesticides and PTP in water environments. Although further method development such as addition of detectable substances, estimation of recovery ratio in SPE procedure and evaluation of matrix effect in LC-MS/MS analysis are required, this analytical method can be a powerful tool in understanding the environmental fate of pesticides and PTP.

\section{ACKNOWLEDGEMENTS}

This research was supported by the Environment Research and Technology Development Fund (B-1104) of the Ministry of the Environment, Japan.

\section{REFERENCES}

Albanis T. A., Hela D. G., Sakellarides T. M. and Konstantinou I. K. (1998) Monitoring of pesticide residues and their metabolites in surface and underground waters of Imathia (N. Greece) by means of solid-phase extraction disks and gas chromatography. Journal of Chromatography A, 823(1-2), 59-71.

Alder L., Greulich K., Kempe G. and Vieth B. (2006) Residue analysis of 500 high priority pesticides : Better by GC-MS or LC-MS/MS? Mass Spectrometry Reviews, 25(6), 838-865.

Hladik M. L., Bouwer E. J. and Roberts A. L. (2008) Neutral chloroacetamide herbicide degradates and related compounds in Midwestern United States drinking water sources. Science of the Total Environment, 390(1), 155-165.

Iwafune T., Inao K., Horio T., Iwasaki N., Yokoyama A. and Nagai T. (2010) Behavior of paddy pesticides and major metabolites in the Sakura River, Ibaraki, Japan. Journal of Pesticide Science, 35(2), 114-123.

Japan Plant Protection Association (2007) Directory of agrichemicals, revised edition 2008, Japan Plant Protection Association, Tokyo, Japan. (in Japanese)

Kadokami K., Tanada K., Taneda K. and Nakagawa K. (2004) Development of a novel GC/MS database for simultaneous determination of hazardous chemicals. Bunseki Kagaku, 53(6), 581-588. (in Japanese)

Kameya T., Saito M., Kondo T., Toriumi W., Fujie K., Matsushita T. and Takanashi H. (2012) Detection of fenitrothion and its degradation product 3-methyl-4-nitrophenol in water environment. Journal of Water and Environment Technology, 10, 427-436.

King R., Bonfiglio R., Fernandez-Metzler C., Miller-Stein C. and Olah T. (2000) Mechanistic investigation of ionization suppression in electrospray ionization. Journal of the American Society for Mass Spectrometry, 11(11), 942-950.

Kishida M., Kumabe T., Takanashi H., Nakajima T., Ohki A., Miyake Y. and Kameya T. (2010) Chlorination by-products of fenitrothion. Water Science and Technology, 62(1), 85-91. 
Maragou N. C., Thomaidis N. S. and Koupparis M. A. (2011) Optimization and comparison of ESI and APCI LC-MS/MS methods: a case study of irgarol 1051, diuron, and their degradation products in environmental samples. Journal of the American Society for Mass Spectrometry, 22(10), 1826-1838.

Ministry of Health, Labour and Welfare(2003) Regulation of agrochemicals in drinking water. http://www.mhlw.go.jp/topics/bukyoku/kenkou/suido/suishitsu/05.html. (accessed April 10, 2012) (in Japanese)

Mol H. G. J., van Dam R. C. J. and Steijger O. M. (2003) Determination of polar organophosphorus pesticides in vegetables and fruits using liquid chromatography with tandem mass spectrometry : selection of extraction solvent. Journal of Chromatography A, 1015(1-2), 119-127.

U. S. Geological Survey (2003) Water-quality assessment of the Eastern Iowa Basins: Selected pesticides and pesticide degradates in steams, 1996-98. Water-Resources Investigations Report 03-4075, U. S. Geological Survey, Reston, VA, USA.

Wick A., Fink G. and Ternes T. A. (2010) Comparison of electrospray ionization and atmospheric pressure chemical ionization for multi-residue analysis of biocides, UV-filters and benzothiazoles in aqueous matrices and activated sludge by liquid chromatography-tandem mass spectrometry. Journal of Chromatography A, 1217(14), 2088-2103. 